\title{
Safety analysis and complications of condylar screws in a single-surgeon series of 250 occipitocervical fusions
}

\author{
Sharon Ka Po. Tam ${ }^{1} \cdot$ Paolo A. Bolognese ${ }^{2} \cdot$ Roger W. Kula $^{2} \cdot$ Andrew Brodbelt $^{3} \cdot$ Mansoor Foroughi $^{1}$. \\ Marat Avshalumov ${ }^{4}$. Denmark Mugutso ${ }^{4} \cdot$ Ilene Ruhoy $^{5}$
}

Received: 5 June 2021 / Accepted: 24 October 2021 / Published online: 25 November 2021

(c) The Author(s) 2021

\begin{abstract}
Objective Condylar screw fixation is a rescue technique and an alternative to the conventional configuration of occipitocervical fusion. Condylar screws are utilized when previous surgical bone removal along the supraocciput has occurred which makes anchoring of a traditional barplate technically difficult or impossible. However, the challenging dissection of $\mathrm{C} 0-1$ necessary for condylar screw fixation and the concerns about possible complications have, thus far, prevented the acquisition of large surgical series utilizing occipital condylar screws. In the largest case series to date, this paper aims to evaluate the safety profile and complications of condylar screw fixation for occipitocervical fusion.

Methods A retrospective safety and complication-based analysis of occipitocervical fusion via condylar screws fixation was performed.

Results A total of 250 patients underwent occipitocervical fusions using 500 condylar screws between September 2012 and September 2018. No condylar screw pullouts, or vertebral artery impingements were observed in this series. The sacrifice of condylar veins during the dissection at $\mathrm{C} 0-1$ did not cause any venous stroke. Hypotrophic condyles were found in $36.4 \%$ (91 of the 250) cases and did not prevent the insertion of condylar screws. Two transient hypoglossal deficits occurred at the beginning of this surgical series and were followed by recovery a few months later. Corrective strategies were effective in preventing further hypoglossal injuries.

Conclusions This surgical series suggests that the use of condylar screws fixation is a relatively safe and reliable option for OC fusion in both adult and pediatric patients. Methodical dissection of anatomical landmarks, intraoperative imaging, and neurophysiologic monitoring allowed the safe execution of the largest series of condylar screws reported to date. Separate contributions will follow in the future to provide details about the long-term clinical outcome of this series.
\end{abstract}

Keywords Occipitocervical fusion $\cdot$ Occipital condyle screw $\cdot$ Occipital condyle $\cdot$ Cranial vertebral fixation

This article is part of the Topical Collection on Neurosurgery general

Paolo A. Bolognese

pbolognese@chiarinsc.com

1 Royal Sussex County Hospital, Brighton and Sussex University Hospitals NHS Trust, Brighton, UK

2 Division of Neurosurgery, Chiari/EDS Neurosurgical Center, Mount Sinai South Nassau, Oceanside, NY, USA

3 Division of Neurosurgery, The Walton Centre NHS Foundation Trust, Liverpool, UK

4 Neurological Surgery Professional Corporation, Rockville Centre, NY, USA

5 Division of Neurology, Chiari/EDS Neurosurgical Center, Mount Sinai South Nassau, Oceanside, NY, USA

\section{Introduction}

Occipito-cervical (OC) fusions are used to treat a variety of pathologies affecting the craniocervical junction $[2,5$, $7,8,20]$.

Condylar screws have been recently introduced as a rescue technique for OC fusions, whenever an existing craniectomy, or a fractured or thin supraocciput limit the available fixation points to the occipital squama $[1,21]$. Concerns regarding potential complications have slowed the use of this technique thus far. In this study, we present the complications and safety analysis of a single-surgeon series of 250 occipitocervical fusions (500 condylar screws). 


\section{Methods}

\section{Inclusion criteria}

Clinical criteria: (1) Karnofsky score $\leq 70$, after failure of conservative management, and (2) $75 \%$ improvement of chief complaints from the baseline, during invasive cervical traction.

Plus one or more of the following radiological criteria: (1) basilar impression or basilar invagination; (2) clivo-axial angle (CXA) of $135^{\circ}$ or below, on neutral imaging studies (MRI or 2DCT); (3) pB-C2 of $8.5 \mathrm{~mm}$ or above; and (4) dynamic basion dens interval (BDI) of $2.0 \mathrm{~mm}$ or more, as obtained during invasive cervical traction, and calculated by subtracting the BDI at end traction with the BDI off traction, both being measured in the sitting position.

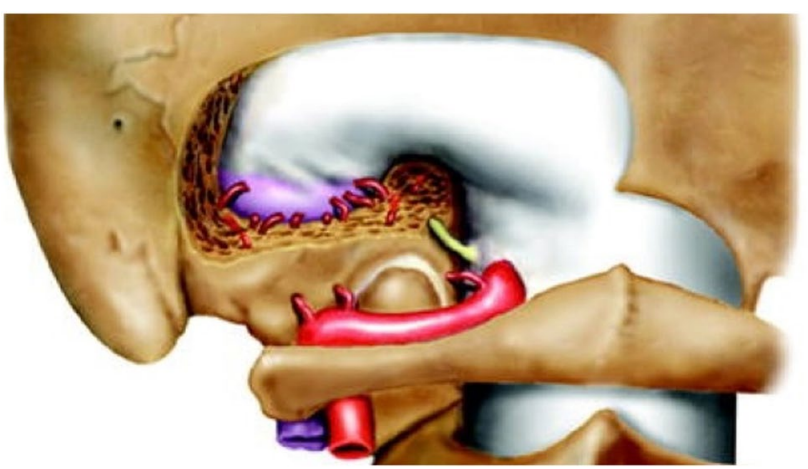

Fig. 1 Sectional anatomy of occipital condyle

\section{Radiological studies}

OsiriX@ software was used on preoperative imaging to measure shape and dimension of the condylar anatomy, length and width of the bony corridors planned for screw insertion, and the extension of surgical bone defects (Fig. 1).

\section{Aspects of surgical technique}

Over time, the entry point was shifted from the top to the middle third of the condyle, to avoid injury to the hypoglossal, especially with hypoplastic condyles. The sacrifice of the occipital emissary veins was key for an extensive dissection of the condyles, down to the $\mathrm{C} 0-\mathrm{C} 1$ space, which was violated to promote fusion within the joint. The hand drill was aimed around $10^{\circ}$ medially, with variations dictated by the individual anatomy. The sagittal trajectory was aimed towards the basion under fluoroscopic guidance, with simultaneous EMG feedback from cranial nerve XII (Fig. 2).

Lag screws of $34 \mathrm{~mm}$ in length and 3.5 in diameter (Medtronic Vertex System) were inserted in the condyles, aiming to a bicortical purchase, with bone depths ranging from 18 to $22 \mathrm{~mm}$. The insertion was followed by Doppler ultrasound examination of the vertebral arteries. Screw stimulation of the condylar screws was used after the first 25 cases, with a safety threshold assumed at $2.8 \mathrm{~m}$ [15].

In most cases, occipitocervical constructs comprised of condylar, $\mathrm{C} 1$ lateral mass, and $\mathrm{C} 2$ pedicle screws. The venous plexus at $\mathrm{C} 1-2$ was coagulated. The $\mathrm{C} 2$ ganglion was dissected and cut.

The condylar trajectories were checked with intraoperative CT scans. Two cobalt-chrome bars (3-4 cm long) were positioned in the screwheads bilaterally and locked in place
Fig. 2 A-C Orthogonal 2D reconstructions (A sagittal, B axial, $\mathbf{C}$ coronal)
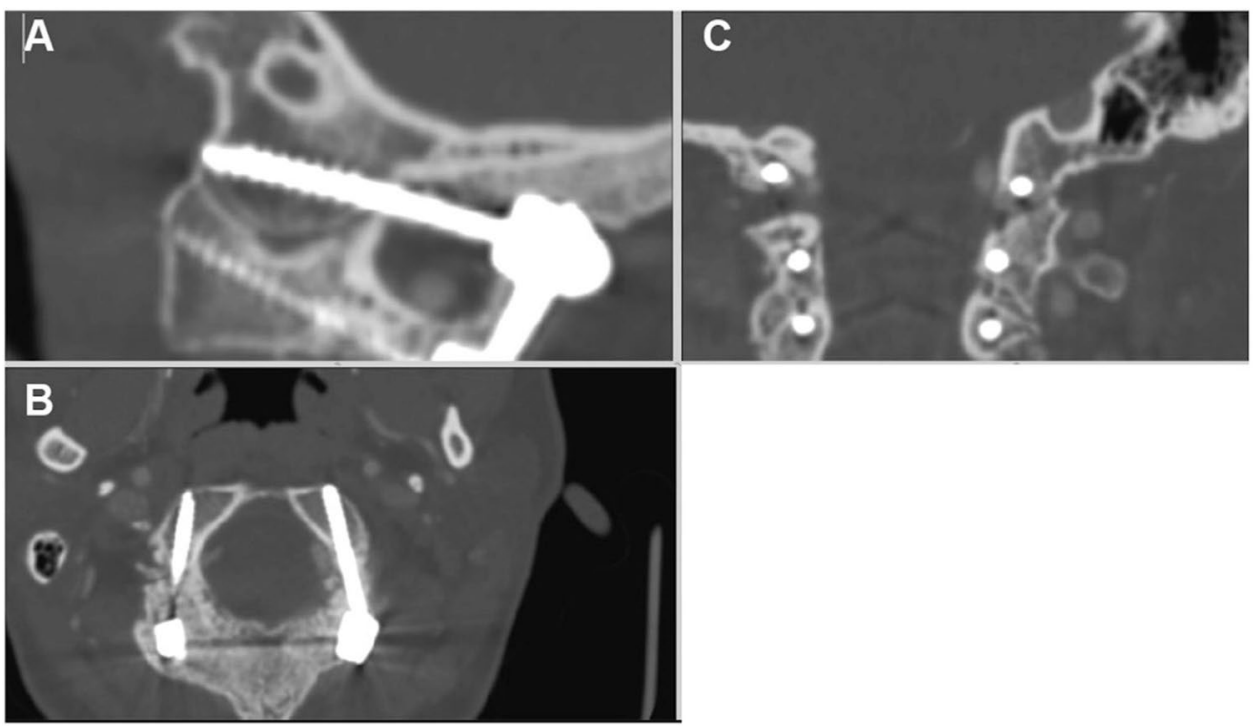
with set screws. A slight bending and/or a side connector at $\mathrm{C} 1$ were required in some cases to obtain the best fit. A finely ground-up mix comprised of crushed cancellous allogenous cadaveric bone, autologous bone, Progenic gel, Mastergraft, and BMP-2 were laid over the hardware and the decorticated bone. BMP-2 was excluded in pediatric patients.

\section{Follow-up}

All patients were scheduled for follow-up at 6 and 12 months postoperatively with MRI and CT imaging and then additional periodic follow-ups.

Of the 250 patients, 14 patients were lost to follow-up. One hundred twenty-five patients of the series have already passed the 5-year postoperative mark.

\section{Data acquisition and statistical analysis}

The following data were tracked: (1) age and sex, (2) integrity of hypoglossal nerves, (3) integrity of vertebral arteries, (4) effects from the sacrifice of condylar veins, (5) hypoplastic condyles, (6) large suboccipital craniectomies, (7) congenitally fused $\mathrm{C} 0-1,(8)$ post-surgical softening around the condylar screws, (9) post-surgical hardware breakdown, (10) post-surgical metal fatigue, (11) post-surgical painful profile, and (12) post-surgical occipital neuralgia.

Descriptive statistics were applied.

\section{Institutional Review Board approval}

The retrospective record review pertinent to this study was approved by the Internal Review Board of the two Institutions where the surgeries took place. (IRB \#13-655B: North Shore University Hospital - Northwell, Manhasset (NY) and WIRB \#1,276,110: Mount Sinai South Nassau - Mount Sinai-Oceanside (NY)).

\section{Results}

\section{Patient population}

Two hundred fifty patients underwent $\mathrm{OC}$ fusion using a total of 500 condylar screws between September 2012 and September 2018. Two hundred seventeen patients were females. The mean age was $36 \pm 13.4 \mathrm{SD}$, ranging from 6 to 75.23 patients were below 18 years of age (ranging 6 to 17). Forty-four cases were revision surgeries from a former barplate configuration. Indications for revision operations included painful profile, metal fatigue, or bar-plate breakdown, alone or in combination. One hundred eighty patients $(72 \%)$ had a formal diagnosis or clinical evidence of a connective tissue disorder. One hundred twenty-three patients $(49.2 \%)$ had a suboccipital craniectomy to address Chiari I malformation as a comorbidity, thus satisfying the diagnostic criteria for Complex Chiari.

Complex Chiari was first described by Brockmeyer et al. and consists in a Chiari I malformation combined with an anatomical or functional disorder of the craniocervical junction [4]. The diagnostic prevalence of connective tissue disorder and Chiari I malformation in our series was an effect of the primary focus of our center.

\section{Skeletal issues}

Hypoplastic condyles were identified in 91 out of the 250 patients (36.4\%) (Table 1), but this finding did not prevent the condylar screw insertion in this series.

Five cases had large suboccipital craniectomies extending up to the transverse sinuses and laterally to the sigmoid sinuses. In 97 out of the 123 patients with former Chiari decompressive surgery, a thickness of less than $2 \mathrm{~mm}$ residual available supraocciput was documented.

The occipital condyles and $\mathrm{C} 1$ were congenitally fused in two cases, and a single screw was inserted through these conjoined bony elements.

\section{Vascular issues}

Condylar screws did not cause impingements or stenoses of the vertebral arteries in our study. There was no clinical evidence of stroke in the vertebral distribution attributable to the use of condylar screws. No clinical evidence of venous stroke was detected during the early postoperative period, or later in follow-up.

\section{Hardware issues}

No condylar screw related painful profile was recorded in this study. Forty-four patients underwent a revision OC fusion from barplate configuration to condylar fixation. The new hardware was perceived to be more comfortable than the former.

Metal fatigue was not observed. No condylar screw pullout was detected at the 6-month follow-up and beyond. No hardware breakdown was found in this surgical series.

\section{Hypoglossal complications}

Among the 500 condylar screws, two hypoglossal injuries were documented at the beginning of the series. Both cases involved patients with hypoplastic condyles and thin supraocciputs; the latter is considered as a limiting factor 
Table.1 Complications related to Condylar Screws and anatomical features affecting their placement

\begin{tabular}{lll}
\hline & Frequency & Percentage (\%) \\
\hline Direct complications & & 2 \\
Clinical compromise of the hypoglossal nerve & 0 & 0.8 \\
Clinical or hemodynamic effects of vertebral artery impingement & 0 & 0 \\
Venous strokes from the sacrifice of the condylar vein & 0 & 0 \\
Post-surgical softening around the condylar screws at the follow-up imaging & 0 & 0 \\
Post-surgical hardware breakdown & 0 & 0 \\
Post-surgical metal fatigue & 0 & 0 \\
Post-surgical painful profile & 0 & 0 \\
Post-surgical occipital neuralgia & & 36.4 \\
Anatomical features & 91 & 0.8 \\
Presence of hypoplastic condyles & 2 & 2 \\
Presence of congenitally fused C0-1 & 5 & \\
Presence of a large suboccipital craniectomy & & \\
\hline
\end{tabular}

for the use of barplates. The first injury was caused by the screw impinging into the condylar canal. This deficit was not identified until after the operation as the neuromonitoring electrodes were mispositioned intraoperatively. A corrective surgery was performed promptly by screw repositioning through a new pass. A near complete recovery was observed at 6 months following the corrective operation. The second injury was attributed to hand drilling. The neuromonitoring promptly warned the surgeon, who redirected the drilling and the new screw trajectory. The postoperative deficit was moderate and the patient experienced a full recovery by the 6 th postoperative month.

Corrective measures were adopted thereafter: (1) extending the dissection of the condyles, (2) lowering the entry point by $5 \mathrm{~mm}$, and (3) shaving the overlaying supraocciput to allow a lower trajectory.

Three patients with hypoplastic condyles and screw trajectories clear of the hypoglossal canal had transient minimal unilateral tongue fasciculations, which resolved completely within 1-2 days, with no residual deficit.

\section{Complications not directly related to condylar screws}

Seven (2.8\%) hardware revisions (Table 2), 25 (10\%) wound revisions not requiring revision of the hardware (Table 3$)$, and $20(8 \%)$ extensions of the $\mathrm{C} 0-\mathrm{C} 2$ fusion to lower segments within the lower cervical of the thoracic spine were noted in our study (Fig. 3).

\section{Fusion rate}

At 12-month follow-up and beyond, the detected fusion rate was $100 \%$.

\section{Discussion}

Condylar screws have been introduced by Uribe et al. in 2008 as a novel rescue technique for OC fusions, in particular, in patients with history of craniectomy limiting the number and thickness of the available fixation points on the occipital squama [18]. Three trajectories were proposed, with different entry points medial to the condylar fossa to preserve the condylar vein $[6,12,14,17]$. In this series, we

Table.2 List of cases requiring hardware revisions, not caused by condylar screw complications

- OC fusion revision, with osteotomies at C01-2 and repositioning in extension, to facilitate future endotracheal intubations

- OC revision, caused by an infected seroma, after a wound tap performed by a local MD

- OC fusion revision, after progression of rheumatoid arthritis, compromising the bone density at $\mathrm{C} 1$ and $\mathrm{C} 2$

- Broken $\mathrm{C} 2$ pedicle, with vertebral artery occlusion by the ipsilateral $\mathrm{C} 2$ pedicle screw

- OC revision of $\mathrm{C} 2$ screws (from pars to pedicle trajectories)

- Insertion of a crossbar in a former cranio-cervical-thoracic fusion

- Revision of the trajectory of two thoracic screws, in a former cranio-cervical-thoracic fusion 
Table.3 Other complications not related to condylar screws

\begin{tabular}{lll}
\hline & Frequency & Percentage (\%) \\
\hline Wound revisions not requiring hardware revisions & & \\
Subfascial pathologies & & 0.8 \\
Seromas & 2 & 0.8 \\
Hematomas & 2 & 3.6 \\
Infections & 9 & 0.4 \\
Section of a C2 nerve root post-amputation neuroma & 1 & 4.4 \\
Superficial wound dehiscence & 11 & 10 \\
Total & 25 & \\
Caudal extension of the hardware & & 2 \\
Cervical & 5 & 2.8 \\
Thoracic & 7 & 1.6 \\
Cervical with subsequent thoracic & 4 & 6.4 \\
\end{tabular}

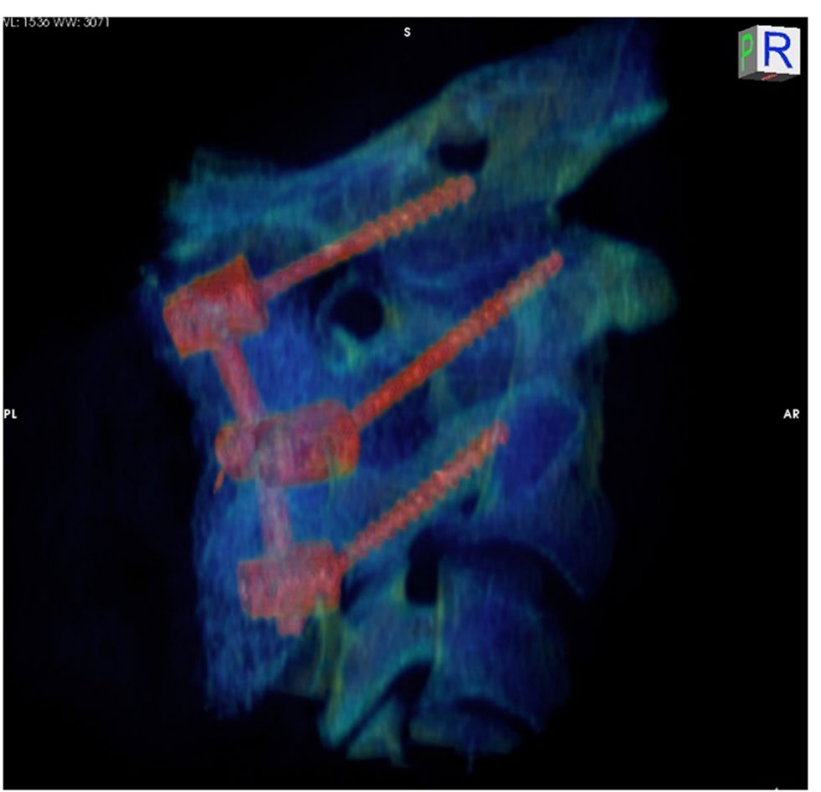

Fig. 3 3D reconstruction of a C0-2 construct with condylar screws

did not have a fix trajectory, and we sacrificed the condylar veins to obtain a better exposure of the condyles.

The persistent interest in this technique has been reflected by a number of CT-based feasibility studies [13, 16, 19] and by recent surgical series which resulted in no complications $[3,10,11]$.

A cadaveric feasibility study by Kirnaz et al. postulated that in $14.1 \%$ of adult OCs and $26.5 \%$ of pediatric OCs studied, placement of condylar screws would have been challenging or unsafe [9]. The anatomy of the condyles did not prevent the insertion of condylar screws in any of our series, despite the fact that hypoplastic condyles were identified in 91 out of the 250 patients (36.4\%).

\section{Biomechanical considerations}

Craniocervical stabilization using condylar and cervical screws has shown comparable results to standard barplate constructs, in terms of range of motion restriction and stiffness, in flexion, extension, lateral bending, and axial rotation (Fig. 4). Uribe et al. believe that decreasing the length of the lever arm of the construct, increasing the length of the screws with improved pullout strength, and use of the condyles as fixation points will provide for a more rigid OC construct [18]. Occipital condylar cervical fixation also covers less of the bony surface than barplates, allowing more surface area for osseous fusion and grafting (Figs. 5, 6 , and 7).

Traditional barplates are L-shaped, curve at the craniocervical junction, and a have a gap between the upper cervical screw and the lowest supraoccipital screw. Metal fatigue tends to occur in the barplate within this curved segment, leading to recurrence of symptoms and in some cases hardware breakdown. The short length of the bar in the condylar construct, the close proximity of the screw heads, and the limited amount of exposed bar between the screw heads theoretically limit the risk of metal fatigue and breakdown. Within the constraints of the short followup, such complications were not observed in this surgical series to date.

When imaged with sagittal and coronal CT reconstructions, the anatomical arrangement of the condyles, the $\mathrm{C} 1$ lateral masses, the $\mathrm{C} 2$ lateral masses, and the screws arranged inside them closely resembles the postsurgical anatomy of an anterior cervical discectomy with fusion and instrumentation, thus suggesting a biomechanical comparison. In the case of long constructs extending from the occiput to the thoracic spine, it is our opinion that the condylar screw fixation should also be augmented by a barplate. 
Fig. 4 A X-rays cervical spine in flexion and extension. Lateral view of broken traditional barplate hardware. B 3D CT of broken traditional barplate, posterior view
Fig. 5 A Intraoperative photo of $\mathrm{C} 0-2$ construct with condylar screws, in a case with concurrent C1-sparing Chiari decompression, prior to the insertion of the bars. B Intraoperative photo of $\mathrm{C} 0-2$ construct with condylar screws, in a case with concurrent Chiari decompression, with $\mathrm{C} 1$ lamiectomy, after the insertion of the bars
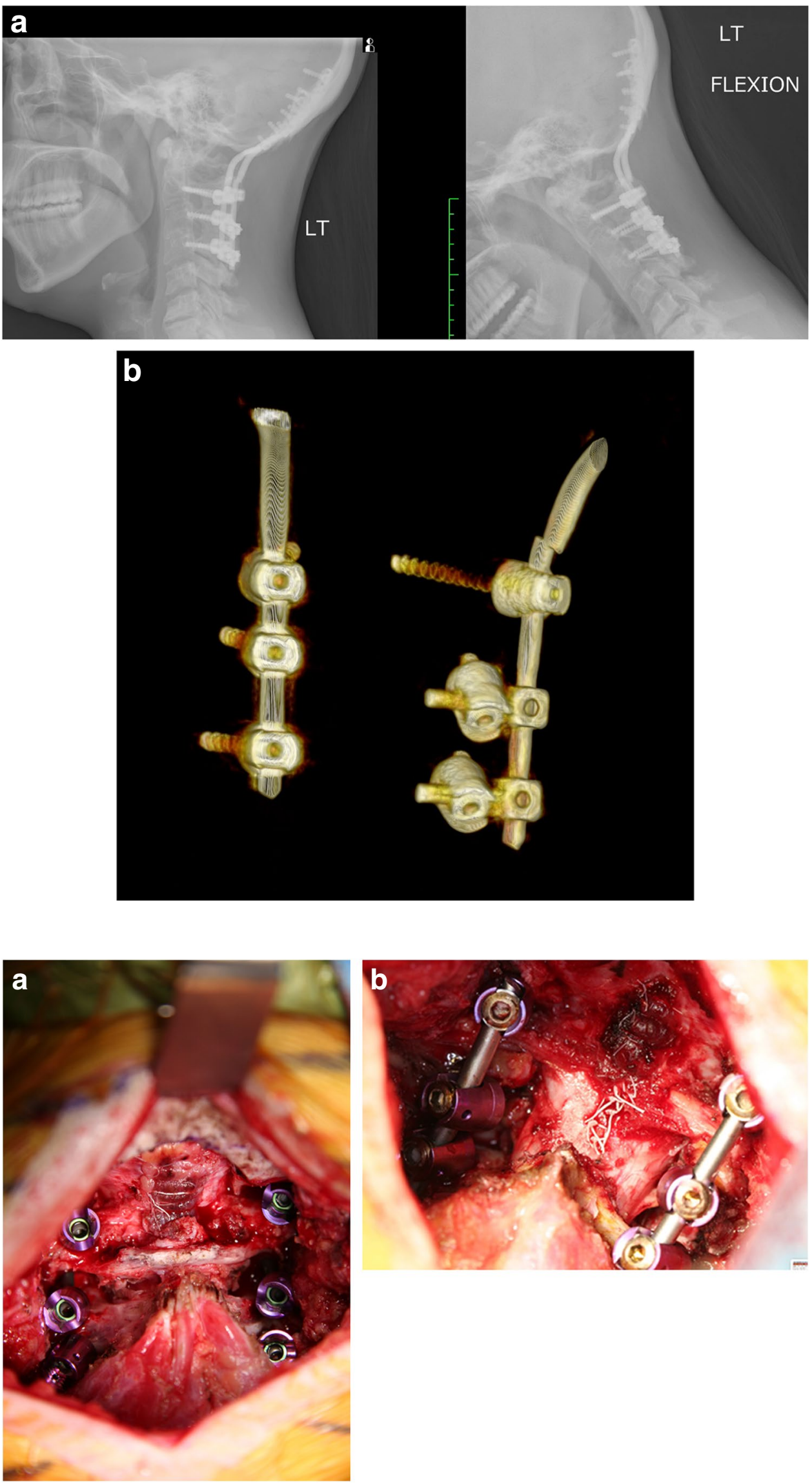

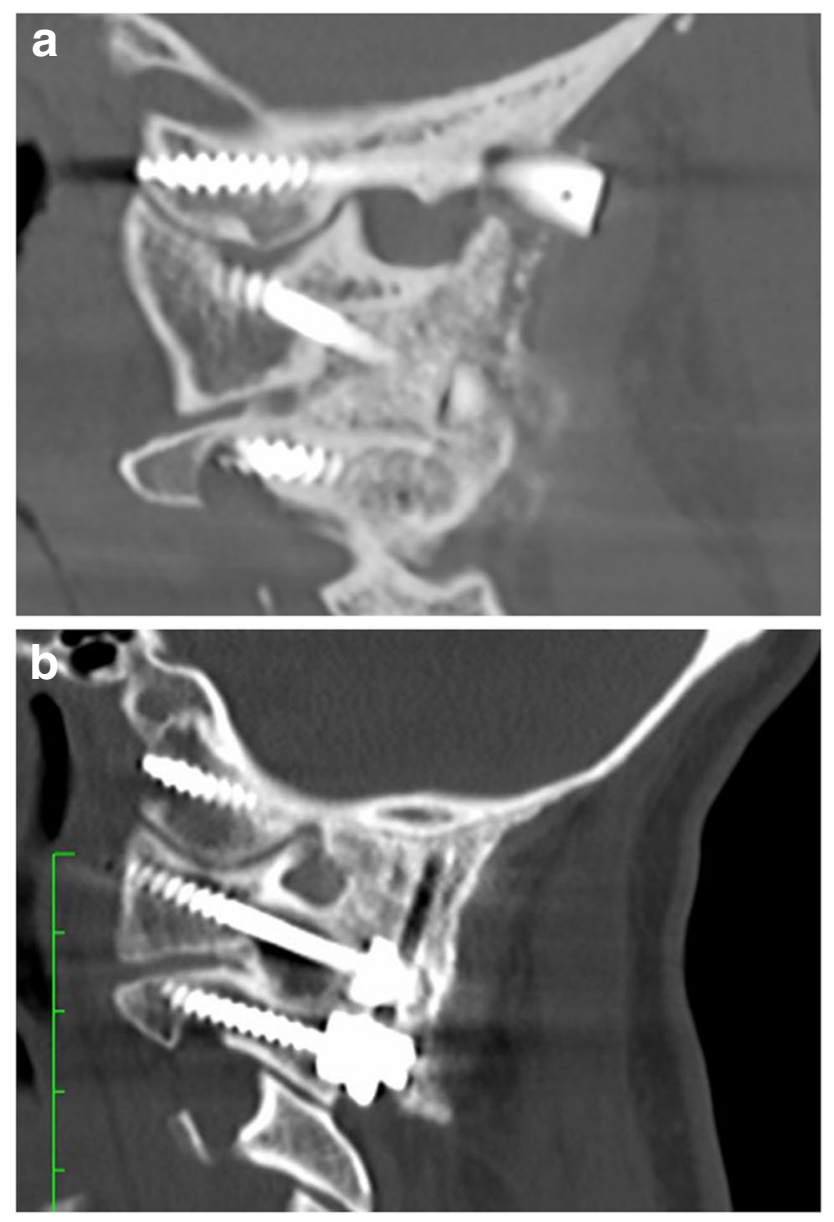

Fig. 6 A Sagittal 2D CT showing condylar screw in hypoplastic condyle. B Sagittal 2D CT with C0-2 construct with condylar screws and extremely thin supraocciput

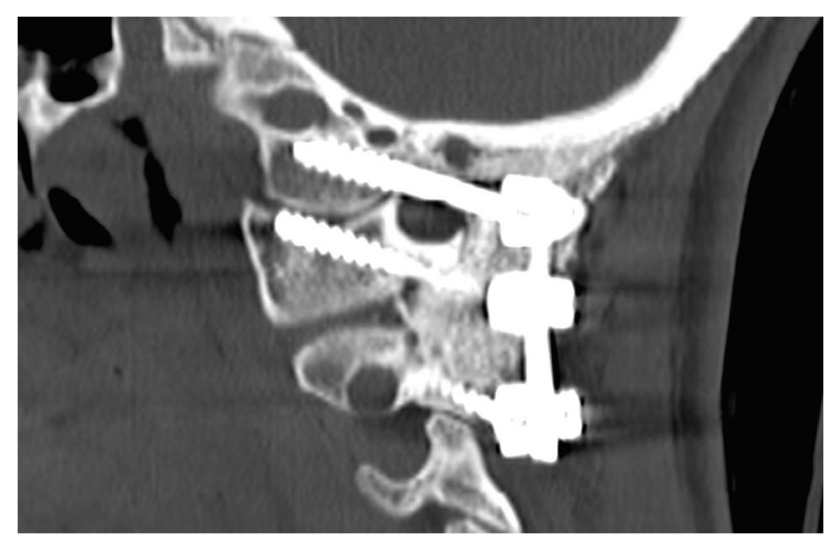

Fig. 7 Sagittal 2D CT with C0-2 construct with condylar screws and mature fusion

\section{Disadvantages and advantages of the technique}

The position of condylar screws is in close proximity to important anatomical structures. The dissection of the condyle is challenging and requires a learning curve. Unlike other authors, we opted to sacrifice the condylar vein, to obtain the following: (1) an increased surface for the bone fusion, (2) an easier access to a wider condyle dissection, and (3) a decreased intraoperative blood loss, since an accidental laceration of a partially dissected condylar vein can be quite difficult to control.

Condylar screws do not require the placement of a screws through the occipital squama, thus avoiding the risk of CSF leakage, intraparenchymal hemorrhages, and the rare occurrence of transverse sinus injuries. Custom bending of the barplate to adapt to the profile of the bone anatomy is no longer required, and the problems caused by the hardware profile (pain, discomfort, muscle spasm, delayed wound healing) are greatly reduced.

The cobalt-chrome rods used in these constructs are short, require minimal or no bending, have a low profile, and allow for a wide fusion surface. Their configuration is likely to result in a long-term decreased incidence of metal fatigue and breakdown, when compared to standard barplate constructs. In addition, the exposure of the condyle allows placement of the graft material directly over the OC joint, thereby providing a graft site superior to that offered with onlay grafting. Despite former concerns, there were no accidental intraoperative lacerations of, or postoperative impingements on the Vertebral arteries, in this series.

Painful profile of the barplate component is a common complaint, linked to the rich local innervation by the greater occipitalis, and the thin layer of overlying soft tissue within the higher segments of the supraocciput.

Another long-term factor is the progressive soft tissue thinning caused by the profile of the barplate.

Unlike barplates, the condylar screw heads are surrounded by less innervated and thick cervical muscle, thus explaining why none of the patients followed up in this surgical series complained about painful profile referable to the condylar screws. In addition, all the 44 patients who underwent a revision of their original $\mathrm{OC}$ fusion from barplate configuration to condylar screw fixation stated that the latter hardware was more comfortable than the original one.

Metal fatigue was not observed in any of the 236 cases which reached follow-up, with 100 of these cases having already passed the 5-year postoperative mark. For the same reasons, no incidence of hardware breakdown was found in this surgical series. The main advantage of this construct versus the classic barplate configuration resides in the following factors: (1) the bar is short and mostly straight, (2) the vector of all the screws is pointing in the same direction, (3) a long portion of the bar is incorporated in the screwheads, and (4) the whole hardware is entirely encompassed by the mature bone fusion. To add anecdotal evidence, 3 patients of this series were involved in catastrophic 
high-energy motor vehicular accidents. The OC hardware remained intact in all three cases.

\section{Technical nuances}

Compared to other authors, we have adopted a lower entry point on the condyle, and a flexible, non-fixed trajectory. This maneuver has allowed lower trajectories within the condyles, remaining clear of the hypoglossal canal even in the case of frequent occurrence of hypoplastic condyles. In the lateral projection, the basion is a reliable reference point to estimate the depth of the condylar screw insertion during fluoroscopic imaging.

The trajectory is mildly converging on the axial plane, with the horizontal pitch modified from case to case on the basis of the preoperative CT images.

The use of neuronavigation is recommended by a number of surgeons who have ventured with condylar screws [3, 10]. After using neuronavigation once, we instead relied on anatomical and fluoroscopic landmarks, which we found easy to master and reliable.

Intraoperative electrophysiologic monitoring is in our opinion a necessary component for the safe execution of this surgery. Moreover, its feedback information was instrumental in accelerating our learning process and in modifying and evolving our surgical technique [15].

\section{Hardware profile and induced discomfort}

The length and the profile of these constructs compare favorably with barplates. In the years in which the main author used the standard barplates construct, several patients had received local block and trigger point injections, and 18 patients had neurostimulators implanted to deal with the local discomfort. None of the 236 patients seen in the follow-up had received similar forms of treatment to date. Another observed but hardly quantifiable by-product of the condylar series has been the decreased incidence of late postoperative muscle spasm in virgin fusion patients.

\section{Bone fusion}

All the CT scans obtained post-operatively have shown solid bone fusions reinforcing the entire span of the hardware. The practice of violating the joint space at $\mathrm{C} 0-1$ has often resulted in solid fusions within these joint spaces. No BMP-2 associated complication was observed.

\section{Complications}

Out of the 500 screw insertion in our series, only two complications were directly caused by condylar screws. In one case, a condylar screw encroached the hypoglossal nerve, while in the other the hypoglossal was involved during hand drilling. The corrective maneuvers, repositioning of the screw and redirection of the drilling, resulted respectively in a near complete and a total improvement of the deficits at the 6-month postoperative mark.

As a result of those adverse events, we soon adopted the following corrective strategies: (1) extending further the dissection of the soft tissues of the condyles, (2) shifting the entry point caudally, and (3) shaving the overlaying supraocciput, to allow a lower trajectory within the condyles.

Vertebral injuries, compressions, or dissections have not occurred in this case series as a direct consequence of the use of condylar screws. Venous infarction did not occur in this surgical series, despite the sacrifice of the occipital emissary vein. The emissary vein should probably be preserved in cases with pathological venous drainage patterns (i.e., Crouzon syndrome).

EDS and other connective disorders are characterized by poor wound healing. As a result of a higher prevalence of these diseases in our cohort, we adopted a lower threshold for superficial wound revisions to take place in an operating room.

\section{Limitations of this study}

Despite the considerable size of this surgical series, the single-surgeon experience may limit the ability to generalize results. A larger series involving more surgeons and more centers would bear a stronger weight. The long-time biomechanical implications and possible delayed complications of the condylar screws of this series need to be further monitored before a definitive opinion can be formulated. There was a narrow spectrum of pathologies and genetic profiles involved in the study, and a relatively homogeneous sex and age distribution, reflecting the referral patterns of our quaternary center but did not represent the larger spectrum of the patients who can benefit from occipitocervical fusion in general. Since neuronavigation was not used in this series, our experience cannot point to the obvious advantages, or the possible shortcomings of this tool, when applied to this surgical technique.

\section{Conclusions}

This surgical series suggests that the use of condylar screws fixation is a relatively safe and reliable option for OC fusion in both adult and pediatric patients. The incidence of complications recorded in this study was low, making this technique less technically challenging and less risky than initially anticipated. Methodical dissection of anatomical landmarks, intraoperative imaging, and neurophysiologic 
monitoring allowed the safe execution of the largest series of condylar screws reported to date. Separate contributions will follow in the future to provide details about the longterm clinical outcome of this series.

\section{Declarations}

Ethical approval The retrospective record review pertinent to this study was approved by the Internal Review Board of the two Institutions where the surgeries took place (IRB \#13-655B and WIRB \#1276110). No patient identifying information used.

Conflict of interest The authors declare no competing interests.

Open Access This article is licensed under a Creative Commons Attribution 4.0 International License, which permits use, sharing, adaptation, distribution and reproduction in any medium or format, as long as you give appropriate credit to the original author(s) and the source, provide a link to the Creative Commons licence, and indicate if changes were made. The images or other third party material in this article are included in the article's Creative Commons licence, unless indicated otherwise in a credit line to the material. If material is not included in the article's Creative Commons licence and your intended use is not permitted by statutory regulation or exceeds the permitted use, you will need to obtain permission directly from the copyright holder. To view a copy of this licence, visit http://creativecommons.org/licenses/by/4.0/.

\section{References}

1. Ahmadian A, Dakwar E, Vale FL, Uribe JS (2014) Occipitocervical fusion via occipital condylar fixation: a clinical case series. J Spinal Disord Tech 27(4):232-236

2. Ahmed R, Traynelis VC, Menezes AH (2008) Fusions at the craniovertebral junction. Child's Nerv Syst 24(10):1209-1224

3. Bekelis K, Duhaime AC, Missios S, Belden C, Simmons N (2010) Placement of occipital condyle screws for occipitocervical fixation in a pediatric patient with occipitocervical instability after decompression for Chiari malformation: Case report. J Neurosurg Pediatr 6(2):171-176

4. Brockmeyer DL (2011) The complex Chiari: issues and management strategies. Neurol Sci. https://doi.org/10.1007/ s10072-011-0690-5

5. Cappuccio M, De Iure F, Amendola L, Paderni S, Bosco G (2013) Occipito-cervical fusion in post-traumatic instability of the upper cervical spine and cranio-cervical junction. Eur Spine J 22(SUPPL.6):900

6. Frankel BM, Hanley M, Vandergrift A, Monroe T, Morgan S, Rumboldt Z (2010) Posterior occipitocervical (C0-3) fusion using polyaxial occipital condyle to cervical spine screw and rod fixation: a radiographic and cadaveric analysis. J Neurosurg Spine 12(5):509-516

7. Grob D (2000) Posterior occipitocervical fusion in rheumatoid arthritis and other instabilities. J. Orthop. Sci. Springer Japan, pp 82-87
8. Hankinson TC, Anderson RCE (2010) Craniovertebral junction abnormalities in down syndrome. Neurosurgery. https://doi.org/ 10.1227/01.NEU.0000365803.22786.F0

9. Kirnaz S, Gerges MM, Rumalla K, Bernardo A, Baaj AA, Greenfield JP (2020) Occipital condyle screw placement in patients with Chiari malformation: a radiographic feasibility analysis and cadaveric demonstration. World Neurosurg 136:470-478

10. Kosnik-Infinger L, Glazier SS, Frankel BM (2014) Occipital condyle to cervical spine fixation in the pediatric population: Report of 4 cases. J Neurosurg Pediatr 13(1):45-53

11. Le TV, Burkett C, Ramos E, Uribe JS (2012) Occipital condyle screw placement and occipitocervical instrumentation using three-dimensional image-guided navigation. J Clin Neurosci 19(5):757-760

12. Le TV, Dakwar E, Hann S, Effio E, Baaj AA, Martinez C, Vale FL, Uribe JS (2011) Computed tomography-based morphometric analysis of the human occipital condyle for occipital condylecervical fusion: Clinical article. J Neurosurg Spine 15(3):328-331

13. Lou Z, Xu D, Wang Y, Ma W, Li G, Ruan C, Zhao H (2018) Feasibility of screw placement on posterior occipital condyle assisted by occipital tangent angulation. Natl Med J China 98(23): 1863-1868

14. La Marca F, Zubay G, Morrison T, Karahalios D (2008) Cadaveric study for placement of occipital condyle screws: technique and effects on surrounding anatomic structures - Laboratory investigation. J Neurosurg Spine 9(4):347-353

15. Mugutso D, Warnecke C, Bolognese P, Avshalumov M (2021) Electromyographic assessment of condylar screw placement during occipitocervical fusion. J Neurosurg Spine 1-10

16. Srivastava A, Nanda G, Mahajan R, Nanda A, Mishra N, Karmaran S, Batra S, Chhabra HS (2017) Computed tomography-based occipital condyle morphometry in an indian population to assess the feasibility of condylar screws for occipitocervical fusion. Asian Spine J 11(6):847-853

17. Uribe JS, Ramos E, Vale F (2008) Feasibility of occipital condyle screw placement for occipitocervical fixation: a cadaveric study and description of a novel technique. J Spinal Disord Tech 21(8):540-546

18 Uribe JS, Ramos E, Youssef AS, Levine N, Turner AWL, Johnson WM, Vale FL (2010) Craniocervical fixation with occipital condyle screws: biomechanical analysis of a novel technique. Spine (Phila Pa 1976) 35(9):931-938

19. Viers AG, Nguyen KD, Moon PX, Forseen SE, Heger IM (2019) Pediatric occipital condyle morphometric analysis using computed tomography with evaluation for occipital condyle screw placement. J Neurosurg Pediatr 23(5):634-638

20. Vieweg U, Meyer B, Schramm J (2001) Tumour surgery of the upper cervical spine - a retrospective study of 13 cases. Acta Neurochir (Wien) 143(3):217-225

21. Winegar CD, Lawrence JP, Friel BC, Fernandez C, Hong J, Maltenfort M, Anderson PLA, Vaccaro AR (2010) A systematic review of occipital cervical fusion: techniques and outcomes: a review. J Neurosurg Spine 13(1):5-16

Publisher's Note Springer Nature remains neutral with regard to jurisdictional claims in published maps and institutional affiliations. 